\title{
Pyriform Fossa Neoplasm
}

National Cancer Institute

\section{Source}

National Cancer Institute. Pyriform Fossa Neoplasm. NCI Thesaurus. Code C4424.

A benign or malignant neoplasm that affects the pyriform sinus. 